\title{
An Optimization of AAV-82Q-Delivered Rat Model of Huntington's Disease
}

\author{
Kyoung-Ha So, ${ }^{1,2, *}$ Jai Ho Choi, ${ }^{3, *}$ Jaisan Islam, ${ }^{4}$ Elina KC, ${ }^{4}$ Hyeong Cheol Moon, ${ }^{4,5}$ So Yoon Won, ${ }^{6}$ Hyong Kyu Kim, ${ }^{6}$ \\ Soochong Kim, ${ }^{7}$ Sang-Hwan Hyun, ${ }^{1,2}$ Young Seok Park ${ }^{1,4,5}$ \\ Institute for Stem Cell \& Regenerative Medicine (ISCRM), Veterinary Medical Center and College of Veterinary Medicine, Chungbuk National \\ University, Cheongju, Korea \\ Laboratory of Veterinary Embryology and Biotechnology (VETEMBIO), ${ }^{2}$ Veterinary Medical Center and College of Veterinary Medicine, \\ Chungbuk National University, Cheongju, Korea \\ Department of Neurosurgery, ${ }^{3}$ Seoul St. Mary's Hospital, College of Medicine, The Catholic University of Korea, Seoul, Korea \\ Department of Medical Neuroscience, ${ }^{4}$ College of Medicine, Chungbuk National University, Cheongju, Korea \\ Department of Neurosurgery, ${ }^{5}$ Chungbuk National University Hospital, Cheongju, Korea \\ Department of Biochemistry and Medical Research Center, ${ }^{6}$ Chungbuk National University, Cheongju, Korea \\ Laboratory of Veterinary Pathology, College of Veterinary Medicine, Chungbuk National University, Cheongju, Korea
}

Objective : No optimum genetic rat Huntington model both neuropathological using an adeno-associated virus (AAV-2) vector vector has been reported to date. We investigated whether direct infection of an AAV2 encoding a fragment of mutant huntingtin (AV2-82Q) into the rat striatum was useful for optimizing the Huntington rat model.

Methods : We prepared ten unilateral models by injecting AAV2-82Q into the right striatum, as well as ten bilateral models. In each group, five rats were assigned to either the $2 \times 10^{12}$ genome copies (GC)/mL of AAV2-82Q ( $\times 1$, low dose) or $2 \times 10^{13} \mathrm{GC} / \mathrm{mL}$ of AAV2-82Q ( $\times 10$, high dose) injection model. Ten unilateral and ten bilateral models injected with AAV-empty were also prepared as control groups. We performed cylinder and stepping tests 2, 4, 6, and 8 weeks after injection, tested EM48 positive mutant huntingtin aggregates.

Results : The high dose of unilateral and bilateral AAV2-82Q model showed a greater decrease in performance on the stepping and cylinder tests. We also observed more prominent EM48-positive mutant huntingtin aggregates in the medium spiny neurons of the high dose of AAV2-82Q injected group.

Conclusion : Based on the results from the present study, high dose of AAV2-82Q is the optimum titer for establishing a Huntington rat model. Delivery of high dose of human AAV2-82Q resulted in the manifestation of Huntington behaviors and optimum expression of the huntingtin protein in vivo.

Key Words : Huntington disease - Adeno-associated virus vector $\cdot$ Huntingtin protein · Neurodegenerative diseases - Gene delivery.

- Received : August 27, 2019 •Revised : October 30, 2019 •Accepted : November 25, 2019

- Address for reprints : Young Seok Park

Department of Neurosurgery, Chungbuk National University Hospital, College of Medicine, Chungbuk National University, 776 1sunhwan-ro, Seowon-gu, Cheongju 28644, Korea

Tel : +82-43-269-6080, Fax : +82-43-273-1614, E-mail : youngseokparkmd@gmail.com, radiosurgerypark@chungbuk.ac.kr, ORCID : https://orcid.org/0000-0001-7685-6292

${ }^{*}$ Choi JH and So KH contributed equally to this work.

This is an Open Access article distributed under the terms of the Creative Commons Attribution Non-Commercial License (http://creativecommons.org/licenses/by-nc/4.0) which permits unrestricted non-commercial use, distribution, and reproduction in any medium, provided the original work is properly cited. 


\section{INTRODUCTION}

Huntington's disease (HD) is an inherited disorder that results in selective neuronal death in the striatum. The primary cause of $\mathrm{HD}$ is a polyglutamine expansion in the huntingtin gene (HTT) that is induced by a repeated cytosine-adenineguanine $(\mathrm{CAG}) \operatorname{codon}^{14)}$. Proteolysis of an N-terminal fragment of mutant HTT isoforms produces aggregates in the nuclei and cytoplasm of spiny projection neurons in the striatum, followed by selective degeneration of the affected neurons ${ }^{32}$. Accordingly, various clinical symptoms develop gradually, including abnormal movements and cognitive dysfunction. Symptoms usually begin between 30 and 50 years of age, and patients with HD survive for an average of 10-20 years after symptom onset before death ${ }^{10,13)}$. Despite our knowledge of the HTT gene and its encoded protein, the exact pathogenesis of HD remains largely unknown, hindering effective treatment. Medical treatments relieve some symptoms, but unfortunately, no cure is available for $\mathrm{HD}^{13)}$.

A proper animal model for $\mathrm{HD}$ is essential to determine the exact mechanism of HD and to develop new therapeutic modalities, such as cell therapy. Thus, some investigators have developed animal models, including a drug-induced rat model using quinolinic acid and knock-in and transgenic mouse model $s^{8,27,31,33,34)}$. In addition, in vivo genetic rat models induced by lentiviral-mediated expression of mutant HTT in the striatum have been introduced ${ }^{6,20,26}$. In the present study, we used adeno-associated virus (AAV) to deliver mutant HTT into the rat striatum. AAV has some advantages, including the induction of a weak host immune response, a lack of toxicity in humans, and long-term stability after insertion into host cells compared to lentiviral vectors ${ }^{5,18}$. Previous studies reported the use of AAV for the delivery of $82 \mathrm{Q}^{12)}, 97 \mathrm{Q}^{29)}$, or $138 \mathrm{Q}^{3)}$ into the mouse or rat striatum to generate an HD model; however, these reports only focused on the neuropathological characteristics of HD. To the best of our knowledge, no optimum genetic rat Huntington model using an adeno-associated virus (AAV-2) vector has been reported to date.

We aimed to test whether infection of two doses $\left[2 \times 10^{12}\right.$ genome copies $(\mathrm{GC}) / \mathrm{mL}(\times 1$, low dose $)$ or $2 \times 10^{13} \mathrm{GC} / \mathrm{mL}(\times 10$, high dose)] of a customized AAV2 vector with 82 polyglutamines (AAV2-82Q) into the rat striatum altered optimal Huntington behavior and HTT protein expression. Therefore, we investigated changes in behavioral, neuropathological characteristics following direct infection of AAV2-82Q into the caudate putamen of the dorsal striatum in the rat brain to develop a more stable and useful animal model and to overcome the shortcomings of previous animal models.

\section{MATERIALS AND METHODS}

\section{Animals}

All protocols using animals were approved by the Institutional Animal Care and Use Committee at Chungbuk National University (CBNUR-1013-16, CBNUR-1310-19). Forty female Sprague Dawley rats weighing 250-300 g (Daehanbiolink, Eumseong, Korea) were used in this randomized, double-blind, controlled animal trial. The animals were assigned a group designation on the same day. The animals were housed in a laboratory with a controlled temperature that was maintained on a 12-hour light-dark cycle. Food and water were provided ad libitum.

\section{AAV2 vector}

The components of the AAV2 vector are illustrated in Supplementary Fig. 1. AAV2 is a ssDNA vector that is approximately $4.5 \mathrm{~kb}$ in length. The viral genome comprises two open reading frames and inverted terminal repeats at each end of the DNA strand. We customized pAAV2-CMV-HTT171-82QWPRE (concentration, $2.0 \times 10^{13} \mathrm{GC} / \mathrm{mL}$ ) from the SIRION Foundation (SIRION, Martinsried, Germany). The human huntingtin cDNA encoding for the first 171 amino acids of the protein along with $82 \mathrm{CAG}$ repeats was cloned into transfer vectors with a cytomegalovirus (CMV) internal promoter using a restricted enzyme. The viral preparation was used to infect human $293 \mathrm{~T}$ cells, purified and concentrated on a heparin affinity column. The final titer was determined by quantitative RT-PCR.

\section{Experimental design}

A schematic of the experimental schedule is illustrated in Fig. 1. We divided 40 rats into two experimental groups (20 rats each in the unilateral injection and bilateral injection groups). Each group included four subgroups composed of two AAV-82Q injection groups : $2 \times 10^{12} \mathrm{GC} / \mathrm{mL}(\times 1$, low dose $)$ group, $2 \times 10^{13} \mathrm{GC} / \mathrm{mL}(\times 10$, high dose), and two AAV-GFP 
control groups (Table 1). We performed the stepping and cylinder tests 2, 4, 6, and 8 weeks after the AAV2-82Q injection. At week 10, immunohistochemical staining was performed for detection of neuronal dysfunction and HD protein aggregation.

\section{Injection of the AAV2-82Q vector into the stria- tum}

The stereotaxic viral vector injections (RWD Lifescience San Diego, CA, USA) were performed under anesthesia with a combination of $15 \mathrm{mg} / \mathrm{kg}$ of tiletamine/zolazepam (Zoletil50 ${ }^{\circledR}$; Virbac Lab., Carros, France) and 9 mg/kg of xylazine (Rompun ; Bayer, Seoul, Korea) in saline to reduce handling-induced stress. The animals in each respective subgroup of the unilateral injection group received a $2-\mu \mathrm{L}$ phosphate-buffered saline (PBS), $2 \times 10^{9} \mathrm{GC}(2 \mu \mathrm{L}$ of 10 -fold-diluted AAV2 in PBS), or $2 \times 10^{10} \mathrm{GC}(2 \mu \mathrm{L}$ of AAV2) injection using a microsyringe (Hamilton, NV, USA) into the right caudate putamen at the following coordinates : $0.43 \mathrm{~mm}$ posterior from the bregma, $3.0 \mathrm{~mm}$ lateral to the midline, and $5.4 \mathrm{~mm}$ ventral from the surface of the brain. When the microsyringe reached the tar- get coordinates, we injected PBS or the AAV2-82Q vector at a rate of $0.2 \mu \mathrm{L} / \mathrm{min}$ using an automated micropump (Harvard Apparatus, Holliston, MA, USA) for 10 minutes. After the injection, we waited 5 minutes for absorption and then slowly removed the microsyringe. The skin was closed using a 4-0 nylon suture (Covidien, Seoul, Korea). The animals in the bilateral injection group received PBS or the AAV2-82Q vector in the bilateral caudate putamen using the same method.

\section{Behavioral tests}

We performed two behavioral tests (the stepping and cylinder tests) 2, 4, 6, and 8 weeks after AAV2-82Q vector injection to confirm changes in locomotion according to the injection site. For the stepping test, we used a treadmill apparatus (Panlabs1, Cornella, Spain) to assess dyskinesia in rats. After rats adapted to the treadmill by walking on the treadmill at a speed of $18 \mathrm{~cm} / \mathrm{s}$ for 10 minutes and then resting for $5 \mathrm{~min}$ utes, the examiner firmly grasped and raised the hind limbs and truncus to shift the rat's weight to the forelimbs. We started the treadmill again at a speed of $18 \mathrm{~cm} / \mathrm{s}$ and recorded the number of steps for 20 seconds $^{19)}$. Another test used to as-

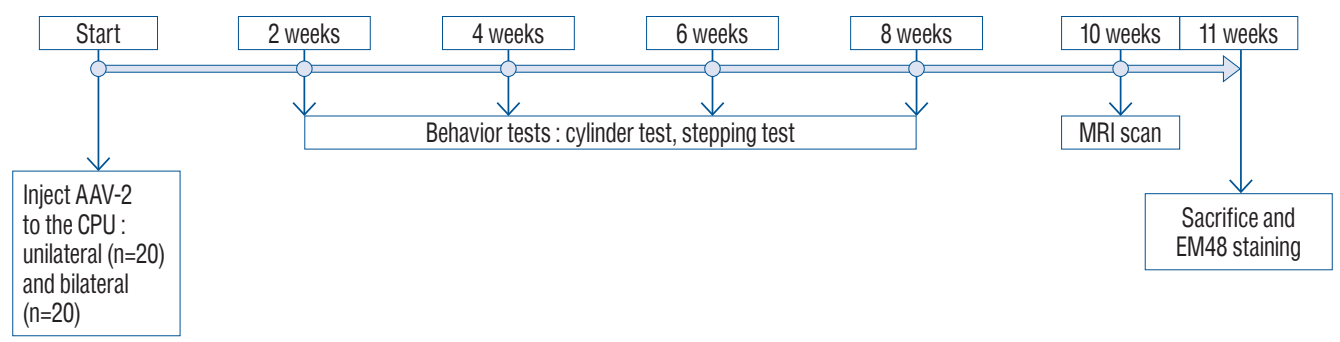

Fig. 1. Schematic of the study protocol. AAV2 : adeno-associated viral vector, CPU : caudate putamen, MRI : magnetic resonance imaging.

Table 1. Experimental group design $(n=40)$

\begin{tabular}{|c|c|c|c|c|c|c|c|c|}
\hline & \multicolumn{4}{|c|}{ Unilateral injection group $(n=20)$} & \multicolumn{4}{|c|}{ Bilateral injection group $(n=20)$} \\
\hline & $\begin{array}{c}\text { Control } \times 1 \\
\text { subgroup } \\
(n=5)\end{array}$ & $\begin{array}{c}\text { Control } \times 10 \\
\text { subgroup } \\
(n=5)\end{array}$ & $\begin{array}{c}\times 1 \\
\text { subgroup } \\
(n=5)\end{array}$ & $\begin{array}{c}\times 10 \\
\text { subgroup } \\
(n=5)\end{array}$ & $\begin{array}{c}\text { Control } \times 1 \\
\text { subgroup } \\
(n=5)\end{array}$ & $\begin{array}{l}\text { Control } \times 10 \\
\text { subgroup } \\
(n=5)\end{array}$ & $\begin{array}{c}\times 1 \\
\text { subgroup } \\
(n=5)\end{array}$ & $\begin{array}{c}\times 10 \\
\text { subgroup } \\
(n=5)\end{array}$ \\
\hline Right striatum & $\begin{array}{l}\text { AAV2-GFP } \\
\left(10^{9} \mathrm{GC} / \mu \mathrm{L}\right. \\
2 \mu \mathrm{L})\end{array}$ & $\begin{array}{l}\text { AAV2-GFP } \\
\left(10^{10} \mathrm{GC} / \mu \mathrm{L}\right. \\
2 \mu \mathrm{L})\end{array}$ & $\begin{array}{l}\text { AAV2-82Q } \\
\left(10^{9} \mathrm{GC} / \mu \mathrm{L}\right. \\
2 \mu \mathrm{L})\end{array}$ & $\begin{array}{l}\text { AAV2-82Q } \\
\left(10^{10} \mathrm{GC} / \mu \mathrm{L}\right. \\
2 \mu \mathrm{L})\end{array}$ & $\begin{array}{l}\text { AAV2-GFP } \\
\left(10^{9} \mathrm{GC} / \mu \mathrm{L}\right. \\
2 \mu \mathrm{L})\end{array}$ & $\begin{array}{l}\text { AAV2-GFP } \\
\left(10^{10} \mathrm{GC} / \mu \mathrm{L}\right. \\
2 \mu \mathrm{L})\end{array}$ & $\begin{array}{l}\text { AAV2-82Q } \\
\left(10^{9} \mathrm{GC} / \mu \mathrm{L}\right. \\
2 \mu \mathrm{L})\end{array}$ & $\begin{array}{l}\text { AAV2-82Q } \\
\left(10^{10} \mathrm{GC} / \mu \mathrm{L},\right. \\
2 \mu \mathrm{L})\end{array}$ \\
\hline Left striatum & & & & & $\begin{array}{l}\text { AAV2-GFP } \\
\left(10^{9} \mathrm{GC} / \mu \mathrm{L}\right. \\
2 \mu \mathrm{L})\end{array}$ & $\begin{array}{l}\text { AAV2-GFP } \\
\left(10^{9} \mathrm{GC} / \mu \mathrm{L}\right. \\
2 \mu \mathrm{L})\end{array}$ & $\begin{array}{l}\text { AAV2-82Q } \\
\left(10^{9} \mathrm{GC} / \mu \mathrm{L}\right. \\
2 \mu \mathrm{L})\end{array}$ & $\begin{array}{l}\text { AAV2-82Q } \\
\left(10^{10} \mathrm{GC} / \mu \mathrm{L},\right. \\
2 \mu \mathrm{L})\end{array}$ \\
\hline $\begin{array}{l}\text { Injection } \\
\text { velocity }\end{array}$ & $0.2 \mu \mathrm{L} / \mathrm{min}$ & & $0.2 \mu \mathrm{L} / \mathrm{min}$ & $0.2 \mu \mathrm{L} / \mathrm{min}$ & $0.2 \mu \mathrm{L} / \mathrm{min}$ & & $0.2 \mu \mathrm{L} / \mathrm{min}$ & $0.2 \mu \mathrm{L} / \mathrm{min}$ \\
\hline
\end{tabular}

AAV2 : adeno-associated viral vector, GC : genome copy 
sess the motor function of the rats was the cylinder test. For this test, we placed the rats into a transparent glass cylinder with a diameter of $20 \mathrm{~cm}$ and a height of $38 \mathrm{~cm}$. The number of times each paw was placed on the cylinder wall during the experiment was recorded (a total of 20 paw placements per trial). We calculated the asymmetric score as (the affected paw+both paws/2) divided by (affected paw+contralateral paw+both paws) ${ }^{11}$.

\section{Histopathology}

Eleven weeks after virus injection, the animals were anesthetized and perfused with 4\% paraformaldehyde (Biosesang, Seongnam, Korea). Then, the brain was removed and immediately immersed in the same fixative for postfixation. After
24 hours, the animal brains were incubated in 30\% sucrose for immunostaining. The staining process was performed as previously described $^{4,7)}$.

Briefly, the rat brain was dehydrated in an ethanol series and embedded in paraffin. Serial coronal sections of the striatum $(10-\mu \mathrm{m}$ thick) were cut with a cryostat and mounted onto slides. Sections were blocked with normal goat serum for 1 hour at room temperature and then incubated overnight with primary antibodies against mouse anti-HTT (1 : 500, clone 1HU-4C8, catalog mAb2166; Merck Millipore, Darmstadt, Germany), mouse anti-HTT protein (1 : 200, clone mEM48; Merck Millipore), mouse anti-ionized calcium-binding adapter molecule 1 (Iba-1) (1 : 200; Abcam, Cambridge, MA, USA), mouse anti-glial fibrillary acidic protein (GFAP) (1 : 200; Ab-
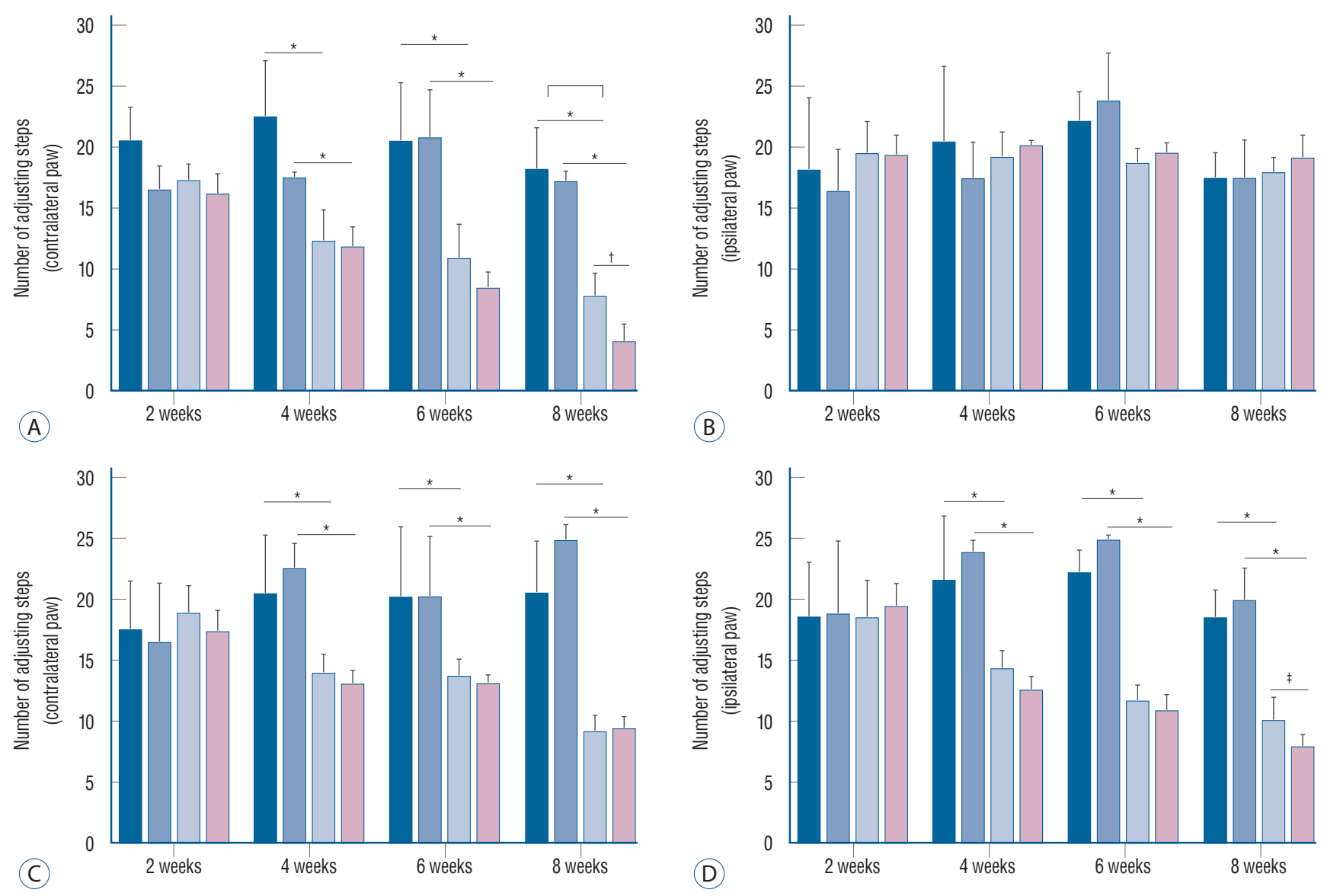

Control $\times 1 \square$ Control $\times 10 \square \mathrm{HD} \times 1 \square \mathrm{HD} \times 10$

Fig. 2. The number of steps in the stepping test recorded at $2,4,6$, and 8 weeks after the AAV2 injection. $A$ : The use of the left paw by the $\times 1$ and $\times 10$ subgroups of the unilateral group as significantly decreased compared with the control subgroup after two weeks. Additionally, the use of the left paw was significantly decreased over time in both the $\times 1$ and $\times 10$ subgroups. At week 8 , a significant difference was observed between the $\times 1$ and $\times 10$ subgroups. B : No differences were observed among the three subgroups. C and D: The use of both paws was significantly decreased in the $\times 1$ and $\times 10$ subgroups of the bilateral group compared to the control subgroup after 4 weeks. At week 8 , a significant difference was observed between the $\times 1$ and $\times 10$ subgroups. Additionally, the use of both paws was significantly decreased over time in both the $\times 1$ and $\times 10$ subgroups. ${ }^{*} p<0.001 .{ }^{\dagger} p<0.01 .{ }^{\ddagger} p<0.05$. 
cam), rabbit anti-oligodendrocyte transcription factor (Olig2) (1 : 200; Abcam), goat anti-NeuN (1:200; Abcam) and rabbit anti-cleaved caspase 3 ( $1: 200$; Abcam). Sections were incubated with the corresponding secondary antibody (Vectastain Elite ABC-HRP Universal Kit; Vector Laboratory, Burlingame, CA, USA) for 1 hour. Then, sections were stained with DAB (Vector Laboratory). The nuclei were stained with hematoxylin. Finally, sections were dehydrated in an ethanol series, mounted with coverslips, dried and examined under a microscope.

Three to five slides per animal were investigated under microscope and the striatal area was identified manually using a rat atlas to count the number of immunohistochemically stained cells. We captured images of the injected area under a $\times 20$ objective lens and counted the EM48-positive cells using ImageJ software (National Institutes of Health, Bethesda, MD, USA).

\section{Statistical analysis}

SPSS version 20.0 (IBM, Armonk, NY, USA) was used for the statistical analysis. We used one-way analysis of variance (ANOVA) with Tukey's post hoc analysis to compare differences among the four subgroups and repeated measures ANOVA with a post hoc analysis to compare repeatedly measured data within each subgroup. The Mann-Whitney U test was used to determine the significance of differences in EM48-positive cell counts between two groups. $p$ values $<0.05$ were considered significant differences.

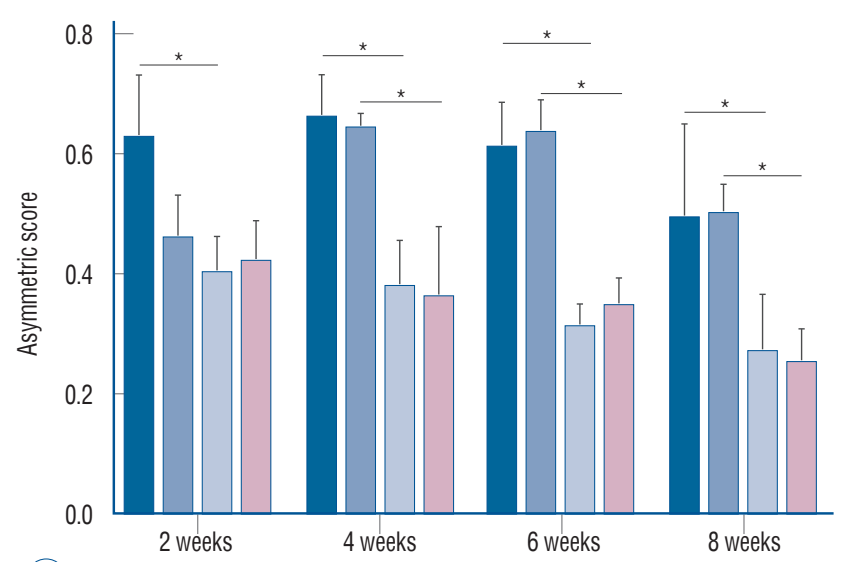

\section{RESULTS}

\section{Changes in rat behaviors}

We conducted two behavioral tests at weeks 2, 4, 6, and 8 after the injection of the AAV2-82Q vector. In the stepping test, the number of steps of the affected paw (contralateral forelimb) was significantly decreased in the $\times 1$ and $\times 10$ subgroups of the unilateral model at 2 weeks compared to the control subgroups, whereas the number of steps taken by the unaffected paws plateaued (Fig. 2A and B). In the bilateral model, the numbers of steps of both the right and left paws were decreased in the $\times 1$ and $\times 10$ subgroups compared to the control subgroups (Fig. 2C and D). A significant difference in the stepping test results for the contralateral forelimb was observed between the unilateral and bilateral $\times 1$ and $\times 10$ subgroups at week 8 after injection (Fig. 2A), but no significant differences were observed between the ipsilateral forelimbs in the bilateral $\times 1$ and $\times 10$ subgroups (Fig. $2 \mathrm{C}$ and D). Repeated measures ANOVA with Tukey's post hoc test revealed a significant decrease in the number of steps taken by the affected paw over time in both the $\times 1$ and $\times 10$ subgroups.

In the cylinder test, we compared the asymmetry scores among the three subgroups (control vs. $\times 1$ vs. $\times 10$ groups) in each unilateral and bilateral group. The asymmetry scores of the unilateral $\times 1$ and $\times 10$ subgroups were significantly decreased at 4 weeks after virus injection compared to the control subgroup. In the bilateral group, the asymmetry score did

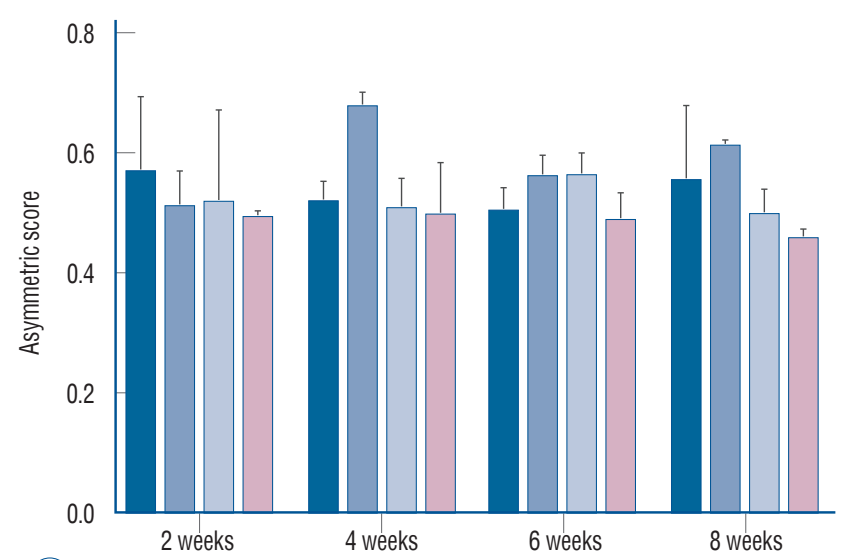

(B)

Control $\times 1 \square$ Control $\times 10 \square \mathrm{HD} \times 1 \square \mathrm{HD} \times 10$

Fig. 3. The asymmetry scores for the cylinder test at $2,4,6$, and 8 weeks after the AAV 2 injection. $A$ : The asymmetry scores of the $\times 1$ and $\times 10$ subgroups of the unilateral group were significantly decreased compared with the control subgroup at 6 and 8 weeks. B : The asymmetry scores did not differ among the three subgroups of the bilateral group. ${ }^{*} p<0.001$. 


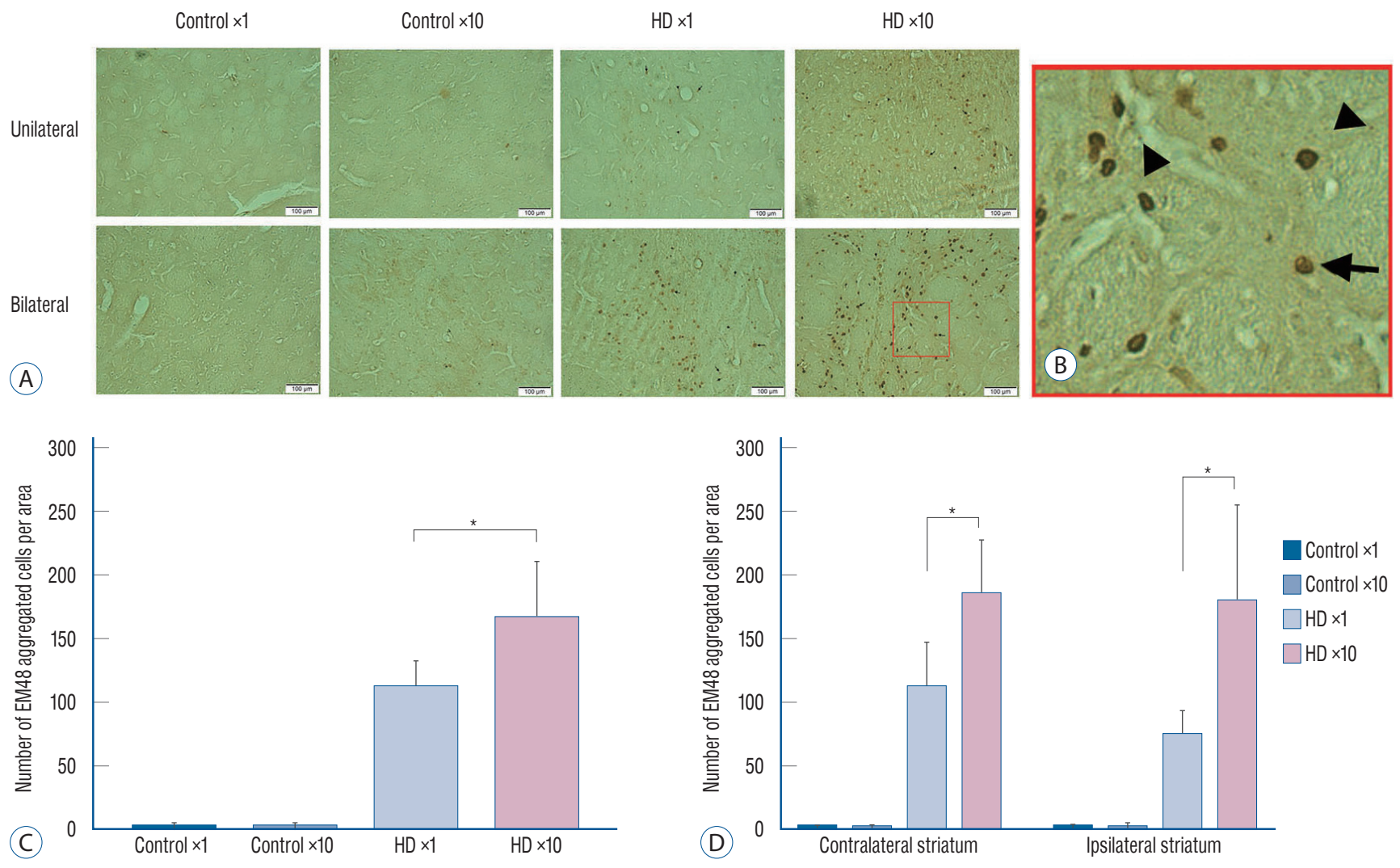

Fig. 4. Immunohistochemical staining with the EM48 antibody showed aggregation of the HTT protein in the striatum of the HD rats. A and B : Formation of mutant HTT detected by the EM48 antibody at 11 weeks after AAV2 injection into the contralateral and ipsilateral striatum of the HD rats. Arrows indicate intranuclear aggregates, and arrowheads indicate smaller neuropil aggregates outside the nucleus. C and D : The number of EM48 aggregated cells counted was significantly different between the $\mathrm{HD} \times 1$ and $\mathrm{HD} \times 10$ subgroups in unilateral ipsilateral striatum (C) and bilateral striata (D) (one-way ANOVA with Turkey's post-hoc test). ${ }^{*} p<0.05$. HTT : huntingtin gene, HD : Huntington's disease, AAV2 : adeno-associated viral vector, ANOVA : analysis of variance.

not differ between the control and injection groups. Additionally, no significant difference was observed in the asymmetry score between the $\times 1$ and $\times 10$ subgroups in the unilateral group (Fig. 3).

\section{Histopathological changes and EM48 aggrega- tion}

We injected $2 \mu \mathrm{L}$ of PBS into the contralateral striatum and $2 \mu \mathrm{L}$ of AAV2-82Q into the ipsilateral striatum of the unilateral $\times 1$ and $\times 10$ subgroups, whereas $2 \mu \mathrm{L}$ of AAV2-82Q were injected into both sides in the bilateral $\times 1$ and $\times 10$ subgroups. We counted the number of cells expressing EM48 under the microscope at $20 \times$ magnification. The mean number of cells counted in both striata of the bilateral injection group was significantly increased in the $\times 10$ subgroup compared with the $\times 1$ subgroup (right hemisphere : $74 \pm 19.78$ vs. $180 \pm 76.11, p=0.035$; left hemisphere : $184 \pm 43.58$ vs. $111 \pm 36.48, p=0.010$ ). In the unilateral group, the number of EM48-positive cells in the right striatum of the $\times 10$ subgroup was significantly higher than in the $\times 1$ subgroup (165.83 \pm 45.15 vs. $110.5 \pm 21.69$, $p=0.029$ ) (Fig. 4). Few cells were labeled with the EM48 antibody in the control subgroup and the contralateral striatum of the unilateral group.

We also detect the expression of huntingtin protein by using anti-huntingtin protein antibody (clone 1HU-4C8, mAb2166) (Fig. 5). The mAb2166 positive cells were found with higher expression in the AAV2-82Q $\times 10$ injected subgroup (Fig. 5D and $\mathrm{H}$ ) than in the $\times 1$ subgroup (Fig. $5 \mathrm{C}$ and $\mathrm{G}$ ). The mAb2166 positive cells was scarcely found in the control subgroups (Fig. 5A, B, E, and F).

The effect of AAV2 infection into microglia, astrocytes, oligodendrocytes, and neurons was shown in Fig. 6 . The brain 
Control $\times 1$
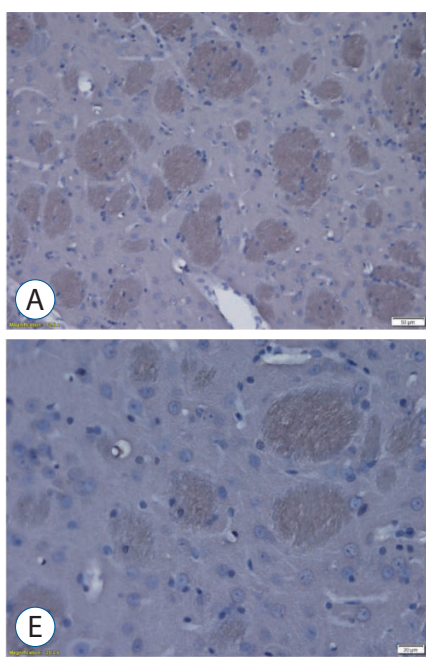

Control $\times 10$
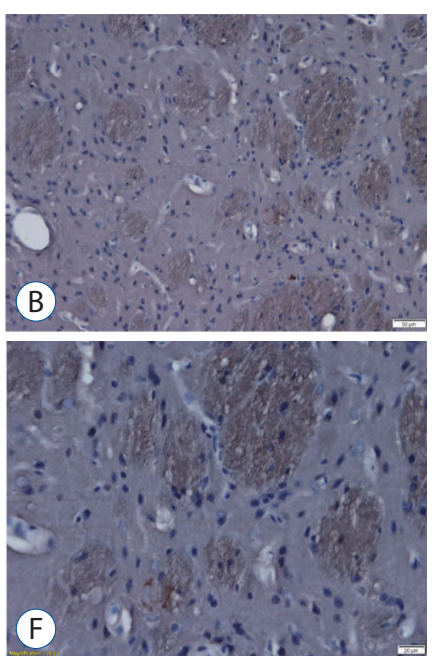

$\mathrm{HD} \times 1$
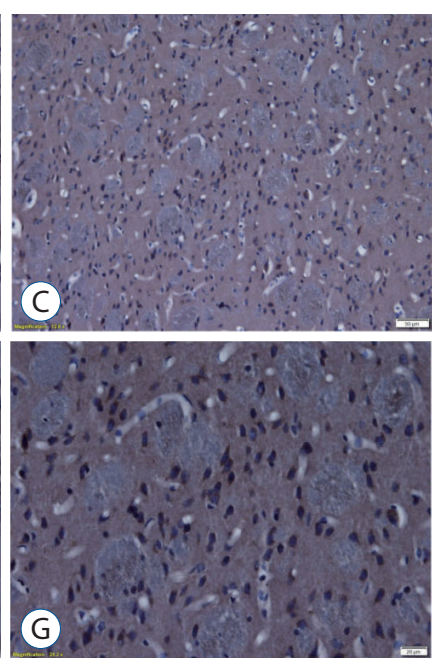

$\mathrm{HD} \times 10$
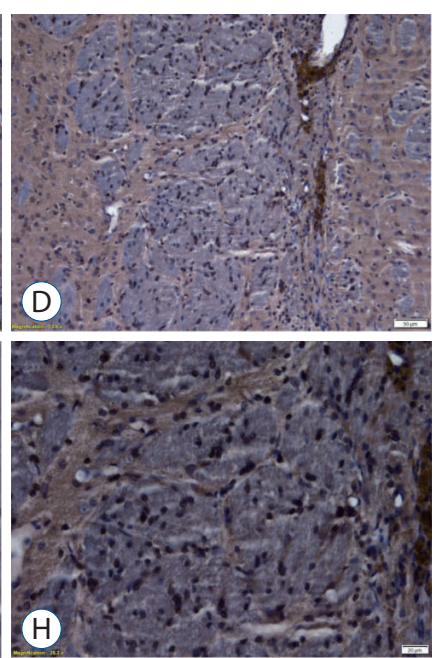

Fig. 5. The huntingtin gene (HTT) protein expression was detected by an HTT-specific antibody (mAB2166) in the striatum of AAV-82Q-infected rat brain. The mAb2166 positive cells (cells with brown color) were found with higher expression in the AAV2-82Q $\times 10$ infected subgroup ( $D$ and $H$ ) than in the $x 1$ subgroup ( $C$ and $G$ ). The mAb2166 was scarcely positive in the control subgroups (A, B, E, and F). Scale bar, A-D : $50 \mu m$; E-H : $20 \mu m$. Brian tissue was embedded in paraffin, and hematoxyin was used. A-D are 10x image and E-H are 20x image. HD : Huntington's disease, AAV2 : adeno-associated virus.

sections showed the activation of microglia (Iba-1 positive) and astrocytes (GFAP positive) in AAV-82Q-injected rats, and more positive cells was observed in the injected groups compared to the control groups. Also, more positive cells were detected in the $\times 10$ subgroup than in the $\times 1$ subgroup. Higher expression of an oligodendrocyte marker (Olig2) and an apoptosis marker (Caspase3) were also detected in the AAV2$82 \mathrm{Q} \times 10$ group than in the control groups and $\times 1$ group. For detection of neuronal dysfunction, the neuronal cell marker (NeuN) was stained that the expressions were slight reduced at HD groups than control groups whereas there were no significant differences between control and mutant groups.

\section{DISCUSSION}

In this study, we developed a new Huntington rat model by directly injecting the caudate putamen with two different viral titers of AAV2-82Q $\left(2 \times 10^{12}\right.$ or $\left.2 \times 10^{13} \mathrm{GC} / \mathrm{mL}\right)$ to determine the optimum viral vector titer to induce an $\mathrm{HD}$ model. We performed locomotor behavioral testing, magnetic resonance imaging scanning, and a neuropathological study to verify that the model was appropriately established.

First, we identified behavioral changes similar to a patient with HD in the affected limb of the rats. The site in the cau- date putamen where we injected AAV2-82Q is the brain structure related to locomotion, learning ability, and anxiety disorders ${ }^{1,21)}$. Previous studies using Parkinson rat models have shown decreased motor function in the stepping test due to damage to the putamen ${ }^{19)}$. We also injected AAV-82Q into the caudate putamen and conducted a stepping test to evaluate motor function. The number of steps in the unilateral and bilateral groups was significantly decreased compared to the control group, and the decrease was exacerbated in rats injected with a higher viral titer. In addition, we performed a cylinder test to assess locomotor dysfunction. The unilaterally injected rats used the ipsilateral right paw more frequently because the right putamen was damaged by AAV2-82Q. However, in the bilateral injection group, dominant use of the right or left paw was not observed, because the bilateral group was injected with AAV2 in both caudate putamens and exhibited did not exhibit more destruction on one side than on the opposite side. Thus, each rat randomly used their preferred paw depending on the dominantly destroyed caudate putamen. These results confirmed impairments in movement and locomotion due to caudate putamen damage.

Second, we produced brain tissue sections and performed immunohistochemistry to histologically verify the presence of mutant HTT, which is the hallmark of HD, and the effect of the AAV2-82Q injection on neurons, microglia, oligodendro- 


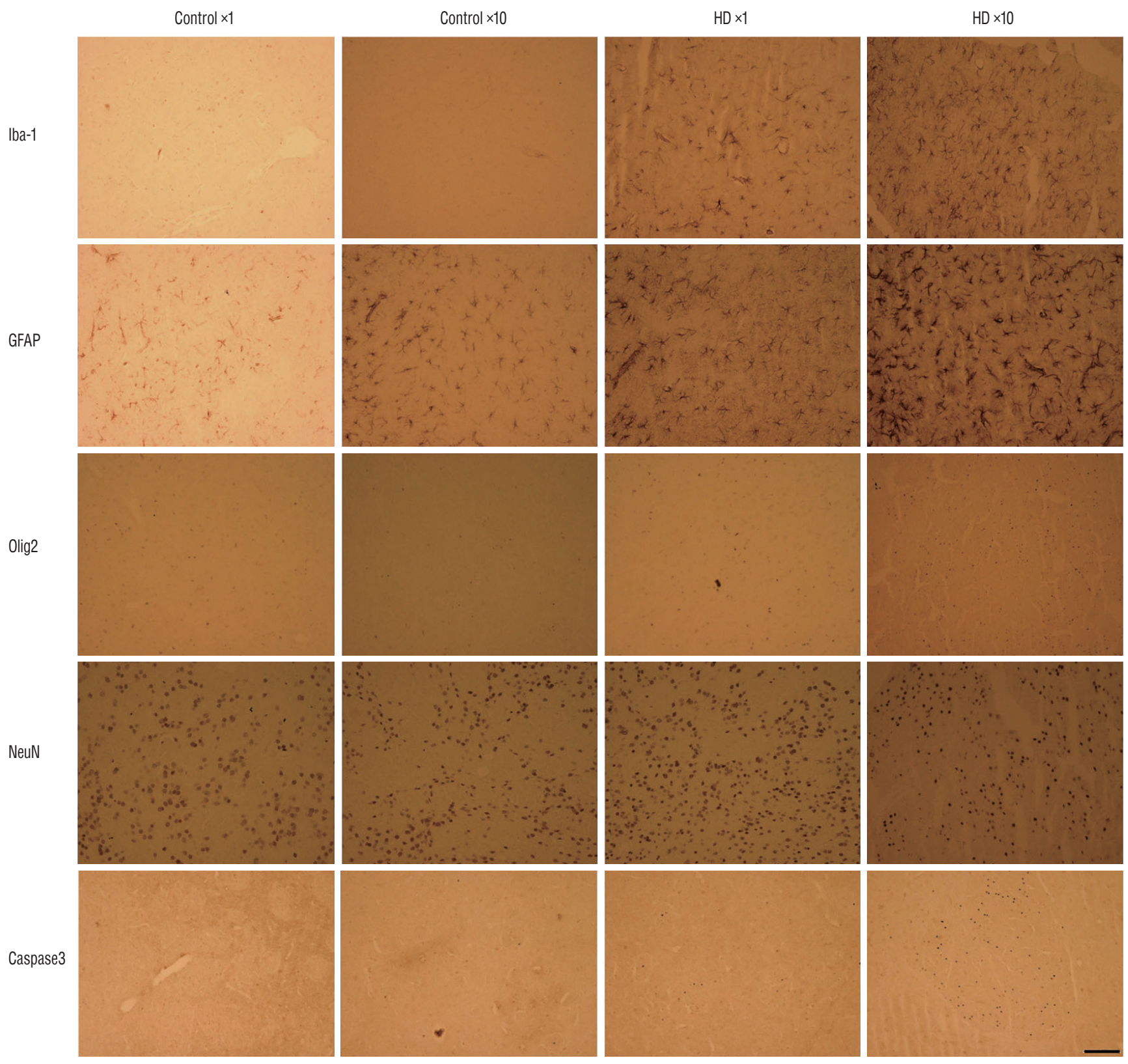

Fig. 6. The histological characters of the AAV- $82 Q$ Huntingtin infected rat brain. Brain sections showed the activation of microglia and astrocytes in AAV-82Q rats. Higher expression of an oligodendrocyte marker (Olig2) and an apoptosis marker (Caspase3) were observed in the AAV2-82Q $\times 10$ group compared to control groups and the $\times 1$ group. The neuronal cell marker (NeuN) was not different between control and injected groups. Scale bar : $50 \mu \mathrm{m}$. $\mathrm{HD}$ : Huntington's disease, AAV2 : adeno-associated virus.

cytes and astrocytes. EM48, a fusion protein antibody directed against the N-terminal region of HTT, was densely aggregated in the AAV2-82Q injection site of the unilateral and bilateral injection groups, whereas little or no aggregation of EM48 was observed in the PBS injection site of the control group. The amount of EM48 aggregation significantly increased with the AAV2-82Q concentration. Our histology re- sults also showed microglia and astrocyte activation in AAV2-82Q-injected rats. This result is similar to the in vivo mouse HD model obtained by stereotaxic infection of AAVDJ containing N171-82Q, which showed that the viral vector infects neurons, microglia, and astrocytes, but not oligodendrocytes $^{12)}$.

Based on these results, we confirm the possibility of a new 
Huntington rat model produced by direct infection of AAV2$82 \mathrm{Q}$ into the striatum. We believe that these animal models overcome the shortcomings of drug induction or other viral vector models.

The drugs used to construct Huntington animal models, such as kainite, quinolinic acid, and 3-nitroproprionic acid, inhibit the mitochondrial energy metabolic enzyme succinate dehydrogenase, which causes cell death by inducing excitotoxicity and subsequent neuronal damage. Consequently, these drugs result in animal models with motor dysfunction and brain pathology similar to $\mathrm{HD}^{8,27)}$. Although the mechanism underlying cell death in the drug-induced models may include a related molecular striatal degeneration pathway, the genetic nature of HD has always called into question the relevance of these neurotoxic lesion models ${ }^{20)}$. Nongenetic models typically induce cell death either by excitotoxic mechanisms or disrupting the mitochondrial machinery ${ }^{22)}$. A clear association between the mechanisms of action of excitotoxins and mitochondrial inhibitors and the genetic cause of HD has not been identified $^{22)}$.

Several transgenic mouse models have been introduced to overcome this drawback of neurotoxic lesion models ${ }^{31,33,34)}$. These models express genomic DNA or cDNAs encoding mutant HTT under the control of endogenous promoters and display many of the typical pathological features of early $\mathrm{HD}^{9,16,24,28,30,35,36)}$. However, they do not replicate the typical pattern of neurodegeneration, such as the loss of spiny medium neurons, even in transgenic mice expressing full-length $\mathrm{HTT}^{9,23)}$. Moreover, fatal adverse effects attributed to overexpression of HTT and premature death that is not related to the striatal lesions have been reported ${ }^{15,23,25)}$.

Recently, animal models using lentiviral vectors encoding mutant HTT have been developed. Lentiviral vectors enable the insertion of target genes into undifferentiated cells and have large vector capacities. However, these vectors have some disadvantages, such as unpredictable loci of viral progeny insertion and the induction of host immune responses ${ }^{2,6,13,17)}$. Because AAV induces a weak immune response compared to lentiviruses, it can be more safely introduced into primates ${ }^{20)}$. Therefore, the use of AAV can be expanded to other primate models, such as a macaque model, which is essential for studies of human diseases. Additionally, this virus has been inserted into both differentiated and undifferentiated cells and exists as an episomal vector, which allows long-term gene expression ${ }^{5,18)}$. Jang et al. ${ }^{12)}$ have been generated an HD mice model using AAV-DJ-N171-82Q mHTT. AAV-DJ and AAV2 have very strong tropism for neurons and fast expression. However, the expression of AAV-DJ can vary a lot depending on the viral titer and purity, while the expression of AAV2 is clearly known.

Although transgenic rodent models and knock-in mice have been produced, these models are not representative of the genetics of the disease in humans, as patients usually have only one normal copy of the HTT gene and one mutated copy. Moreover, additional pathology not associated with this disease has been observed in these models ${ }^{22)}$. The models also have limitations because they are time-consuming and are unlikely to be cost-effective in large mammalian or non-human primate models.

Because the creation of transgenic non-human primates is both time-consuming and costly, the proposed model is particularly attractive for examining complex cognitive and motor behaviors that can best be studied in non-human primates $^{22)}$. A human gene delivery method in an HD model is relatively cost-effective and may not introduce additional pathology, as opposed to transgenic methods; thus, this approach can be widely applied to non-human primates for Huntington research. The proposed method is expected to produce stable rodent or non-human primate Huntington models in the same manner.

In the recent study, we provided two different data sets including behavior tests and histological properties of HD rat models that induced by infecting two doses of AAV2-H171$82 \mathrm{Q}$. It can be used as a basis for translating to large animal HD model.

This study has some limitations. Patients with HD display various numbers of CAG repeats and therefore the AAV-82Q $2 \times 10^{13} \mathrm{GC} / \mathrm{mL}$ infection rat model may not represent a universal Huntington model. Moreover, we did not evaluate specific neuronal markers, such as medium spiny neuron (MSN 1) and gamma-aminobutyric acid (GABA 1), in the striatum and cerebral cortex.

\section{CONCLUSION}

The injection of $2 \times 10^{13} \mathrm{GC} / \mathrm{mL}$ of AAV2-82Q into the rat striatum generates the optimum Huntington rat model rather 
than the infection of $2 \times 10^{12} \mathrm{GC} / \mathrm{mL}$ of AAV2-82Q, and thus this model overcomes the shortcomings of other Huntington's animal models. The delivery of $2 \times 10^{13} \mathrm{GC} / \mathrm{mL}$ of human the AAV2-82 gene resulted in Huntington behaviors and optimum HTT protein expression in vivo. This study would propel to study cell or gene therapy, and overcome disadvantages of existing animal modeling in incurable Huntington disease.

\section{CONFLICTS OF INTEREST}

No potential conflict of interest relevant to this article was reported.

\section{AUTHOR CONTRIBUTIONS}

Conceptualization : YSP

Data curation : KHS, JHC, JI, EKC, HCM, SYW, HKK, SK, $\mathrm{SHH}$

Formal analysis : JHC, KHS, JI

Funding acquisition : YSP

Methodology: KHS, JHC, JI, EKC, HCM, SYW, HKK, SK, SHH

Project administration : YSP, KHS

Visualization : JI, JHC, KHS

Writing - original draft : KHS, JHC, JI, YSP

Writing - review \& editing : KHS, YSP

\section{ORCID}

Kyoung-Ha So

Jai Ho Choi

Jaisan Islam

Elina KC

Hyeong

So Yoon Won

Hyong Kyu Kim

Soochong Kim

Sang-Hwan Hyun https://orcid.org/0000-0001-6011-2555

Young Seok Park https://orcid.org/0000-0001-7685-6292

\section{- Acknowledgements}

This work was supported by the National Research Foundation of Korea (NRF) grant funded by the Korea government (2015H1D3A1066175 [KRF], 2016R1D1A1B03933191, 2017K1A4A3014959 [GRDC, Global Research and Development Center], and 2019R1I1A1A01059554). This study was also supported by Research Fund of Seoul St. Mary's Hospital, The Catholic University of Korea.

\section{- Supplementary materials}

The online-only data supplement is available with this article at https://doi.org/10.3340/jkns.2019.0182.

\section{References}

1. Alexander GE, Crutcher MD : Preparation for movement: neural representations of intended direction in three motor areas of the monkey. J Neurophysiol 64 : 133-150, 1990

2. Cattoglio C, Facchini G, Sartori D, Antonelli A, Miccio A, Cassani B, et al. : Hot spots of retroviral integration in human CD34+ hematopoietic cells. Blood 110 : 1770-1778, 2007

3. Ceccarelli I, Fiengo P, Remelli R, Miragliotta V, Rossini L, Biotti I, et al. : Recombinant Adeno Associated Viral (AAV) vector type 9 delivery of Ex1-Q138-mutant huntingtin in the rat striatum as a short-time model for in vivo studies in drug discovery. Neurobiol Dis 86 : 41-51, 2016

4. Davies SW, Turmaine M, Cozens BA, DiFiglia M, Sharp AH, Ross CA, et al. : Formation of neuronal intranuclear inclusions underlies the neurological dysfunction in mice transgenic for the HD mutation. Cell 90 : 537-548, 1997

5. Daya $\mathrm{S}$, Berns $\mathrm{KI}$ : Gene therapy using adeno-associated virus vectors. Clin Microbiol Rev 21 : 583-593, 2008

6. de Almeida LP, Ross CA, Zala D, Aebischer P, Déglon N : Lentiviralmediated delivery of mutant huntingtin in the striatum of rats induces a selective neuropathology modulated by polyglutamine repeat size, huntingtin expression levels, and protein length. J Neurosci 22 : 3473 3483, 2002

7. DiFiglia M, Sapp E, Chase KO, Davies SW, Bates GP, Vonsattel JP, et al. : Aggregation of huntingtin in neuronal intranuclear inclusions and dystrophic neurites in brain. Science 277 : 1990-1993, 1997

8. Foster AC, Whetsell WO Jr, Bird ED, Schwarcz R : Quinolinic acid phosphoribosyltransferase in human and rat brain: activity in Huntington's disease and in quinolinate-lesioned rat striatum. Brain Res 336 : 207214, 1985

9. Hodgson JG, Agopyan N, Gutekunst CA, Leavitt BR, LePiane F, Singaraja $R$, et al. : A YAC mouse model for Huntington's disease with full-length mutant huntingtin, cytoplasmic toxicity, and selective striatal neurode- 
generation. Neuron 23 : 181-192, 1999

10. Hoth KF, Paulsen JS, Moser DJ, Tranel D, Clark LA, Bechara A : Patients with Huntington's disease have impaired awareness of cognitive, emotional, and functional abilities. J Clin Exp Neuropsychol 29 : 365376, 2007

11. Hua Y, Schallert T, Keep RF, Wu J, Hoff JT, Xi G : Behavioral tests after intracerebral hemorrhage in the rat. Stroke $33: 2478-2484,2002$

12. Jang $M$, Lee $S E$, Cho IH : Adeno-associated viral vector serotype DJmediated overexpression of N171-82Q-mutant huntingtin in the striatum of juvenile mice is a new model for Huntington's disease. Front Cell Neurosci $12: 157,2018$

13. Kim $M$ : Brain Transplantation for Huntington Disease. Tissue Eng Regen Med 2 : 322-326, 2005

14. MacDonald ME, Ambrose CM, Duyao MP, Myers RH, Lin C, Srinidhi L et al. : A novel gene containing a trinucleotide repeat that is expanded and unstable on Huntington's disease chromosomes. The Huntington's Disease Collaborative Research Group. Cell 72 : 971-983, 1993

15. Mangiarini L, Sathasivam K, Mahal A, Mott R, Seller M, Bates GP : Instability of highly expanded CAG repeats in mice transgenic for the Huntington's disease mutation. Nat Genet 15 : 197-200, 1997

16. Mangiarini L, Sathasivam K, Seller M, Cozens B, Harper A, Hetherington $C$, et al. : Exon 1 of the HD gene with an expanded CAG repeat is sufficient to cause a progressive neurological phenotype in transgenic mice. Cell 87 : 493-506, 1996

17. Marini B, Kertesz-Farkas A, Ali H, Lucic B, Lisek K, Manganaro L, et al. : Nuclear architecture dictates HIV-1 integration site selection. Nature $521: 227-231,2015$

18. Nussbaum RL, McInnes RR, Willard HF : Thompson \& Thompson genetics in medicine. Philadelphia : Elsevier Health Sciences, 2015

19. Olsson $M$, Nikkhah $G$, Bentlage $C$, Björklund $A$ : Forelimb akinesia in the rat Parkinson model: differential effects of dopamine agonists and nigral transplants as assessed by a new stepping test. J Neurosci 15(5 Pt 2) : 3863-3875, 1995

20. Palfi S, Brouillet E, Jarraya B, Bloch J, Jan C, Shin M, et al. : Expression of mutated huntingtin fragment in the putamen is sufficient to produce abnormal movement in non-human primates. Mol Ther 15 : 1444-1451, 2007

21. Radua J, van den Heuvel OA, Surguladze S, Mataix-Cols D : Metaanalytical comparison of voxel-based morphometry studies in obsessivecompulsive disorder vs other anxiety disorders. Arch Gen Psychiatry $67: 701-711,2010$

22. Ramaswamy S, McBride JL, Kordower JH : Animal models of Huntington's disease. ILAR J 48 : 356-373, 2007

23. Reddy PH, Charles V, Williams M, Miller G, Whetsell WO Jr, Tagle DA : Transgenic mice expressing mutated full-length HD CDNA: a paradigm for locomotor changes and selective neuronal loss in Huntington's disease. Philos Trans R Soc Lond B Biol Sci 354 : 1035-1045, 1999

24. Reddy PH, Williams M, Charles V, Garrett L, Pike-Buchanan L, Whetsell WO Jr, et al. : Behavioural abnormalities and selective neuronal loss in $\mathrm{HD}$ transgenic mice expressing mutated full-length HD CDNA. Nat Genet 20 : 198-202, 1998

25. Reddy PH, Williams M, Tagle DA : Recent advances in understanding the pathogenesis of Huntington's disease. Trends Neurosci 22 : 248-255, 1999

26. Régulier E, Trottier Y, Perrin V, Aebischer P, Déglon N : Early and reversible neuropathology induced by tetracycline-regulated lentiviral overexpression of mutant huntingtin in rat striatum. Hum Mol Genet 12 : 2827-2836, 2003

27. Sanberg PR, Calderon SF, Giordano M, Tew JM, Norman AB : The quinolinic acid model of Huntington's disease: locomotor abnormalities. Exp Neurol $105:$ 45-53, 1989

28. Schilling G, Becher MW, Sharp AH, Jinnah HA, Duan K, Kotzuk JA, et al. : Intranuclear inclusions and neuritic aggregates in transgenic mice expressing a mutant N-terminal fragment of huntingtin. Hum Mol Genet 8 : 397-407, 1999

29. Senut MC, Suhr ST, Kaspar B, Gage FH : Intraneuronal aggregate formation and cell death after viral expression of expanded polyglutamine tracts in the adult rat brain. J Neurosci $20: 219-229,2000$

30. Shelbourne PF, Killeen N, Hevner RF, Johnston HM, Tecott L, Lewandoski $M$, et al. : A Huntington's disease CAG expansion at the murine Hdh locus is unstable and associated with behavioural abnormalities in mice. Hum Mol Genet 8 : 763-774, 1999

31. Slow EJ, van Raamsdonk J, Rogers D, Coleman SH, Graham RK, Deng $Y$, et al. : Selective striatal neuronal loss in a YAC128 mouse model of Huntington disease. Hum Mol Genet 12 : 1555-1567, 2003

32. Stack EC, Ferrante RJ : Huntington's disease: progress and potential in the field. Expert Opin Investig Drugs 16 : 1933-1953, 2007

33. Stack EC, Kubilus JK, Smith K, Cormier K, Signore SJD, Guelin E, et al. : Chronology of behavioral symptoms and neuropathological sequela in R6/2 Huntington's disease transgenic mice. J Comp Neurol 490 : 354370, 2005

34. Vorisek I, Syka M, Vargova L : Brain diffusivity and structural changes in the R6/2 mouse model of huntington disease. J Neurosci Res 95 : 1474-1484, 2017

35. Wheeler VC, Auerbach W, White JK, Srinidhi J, Auerbach A, Ryan A, et al. : Length-dependent gametic CAG repeat instability in the Huntington's disease knock-in mouse. Hum Mol Genet 8 : 115-122, 1999

36. White JK, Auerbach W, Duyao MP, Vonsattel JP, Gusella JF, Joyner AL, et al. : Huntingtin is required for neurogenesis and is not impaired by the Huntington's disease CAG expansion. Nat Genet 17 : 404-410, 1997 